Pengembangan Rekayasa dan Teknologi, Vol 16, No. 1, Juni 2020, pp 45-51

p-ISSN: 1410-9840 \& e-ISSN: 2580-8850

http://journals.usm.ac.id/index.php/jprt/index

\title{
IMPLEMENTASI SISTEM INFORMASI MANAJEMEN BERBASIS WEBSITE PADA UKM BUBUR BAYI ORGANIK BEBICARE
}

\author{
Priagung Lukmana ${ }^{1,}$ Eki Agtrin Rahmadan ${ }^{2}$, Bambang Nirwanto ${ }^{3}$, Eko Wahyu Abryandoko ${ }^{4}$ \\ ${ }^{1,2,3}$ Fakultas Sains dan Teknik, Universitas Bojonegoro \\ *e-mail: abryandoko@gmail.com
}

\begin{abstract}
Abstrak
Perkembangan teknologi informasi pada bidang industri pada saat ini telah berkembang sangat cepat. Salah satu fungsi dari penerapannya adalah untuk membantu proses kerja agar berjalan lebih efektif dan efisien. Setiap perusahaan tidak terkecuali Pada UKM bubur bayi organik Bebicare, harus mampu berusaha menekan atau mereduksi waktu dan tenaga dalam beberapa proses kerja terutama melalui optimasi monitoring aliran keuangan dalam proses produksi dan penjualan. Sistem Informasi Manajemen merupakan sebuah aplikasi berbasis web sebagai sistem pendukung Manajemen UKM yang dibangun untuk memudahkan pengguna dalam memantau basis data dari keuangan,data inventaris,data produksi,data pengeluaran harian dan data karyawan secara terpusat. Aplikasi ini dibangun dari bahasa pemrograman PHP dengan metode pengembangan berbasis website termodifikasi. Proses tahapan pengembangan ini terbagi menjadi 3 tahapan, yaitu: analisa kebutuhan sistem, implementasi, dan pengujian.dengan tujuan
\end{abstract}

Kata Kunci : Sistem Informasi, Manajemen UKM, Bebicare, website, PHP

Abstract
The development of information technology in the industrial field at this time has been developing very fast. One function of its application is to help the work process to run more effectively and efficiently. Every company is no exception to Bebicare organic baby porridge UKM, it must be able to try to reduce or reduce time and energy in several work processes, especially through optimization of financial flow monitoring in the production and sales process. Management Information System is a web-based application as a support system for UKM Management which was built to facilitate users in monitoring databases of finance, inventory data, production data, daily expenditure data and employee data centrally. This application is built from the PHP programming language with a modified website-based development method. The process of this development stage is divided into 3 stages, namely: system requirements analysis, implementation, and testing.

Keywords: Information Systems, SME Management, Bebicare, websites, PHP.

\section{PENDAHULUAN}

Teknologi internet sudah terbukti merupakan salah satu media informasi yang efektif dan efisien dalam penyebaran informasi yang dapat diakses oleh siapa saja, kapan saja dan dimana saja.

Teknologi internet mempunyai efek yang sangat besar pada perdagangan atau bisnis. Hanya dari rumah atau ruang kantor,para pebisnis dapat memanajemen usahanaya pada layar komputer, mengakses informasinya, mengatur keuangan dan lain sebagainya dengan aplikasi yang tersedia. Para pengusaha kecil dapat menghemat waktu dan biaya karena tidak perlu datang ke kantor atau tempat produksi. Sehingga dari tempat duduk mereka dapat mengambil keputusan dengan cepat. manajemen secara online dapat menghubungkan antara pemimpin perusahaan, manager, admin, dan karyawan tanpa dibatasi oleh suatu ruang dan waktu.

Itu berarti sistem manajemen secara online mempunyai efisiensi dan mobilitas yang tinggi.Sistem manajemen yang selama ini digunakan oleh UKM bubur bayi organik Bebicare adalah dengan cara menulis secara manual, harus bertatap muka untuk mengambil keputusan atau memberi pengumuman. Sistem manajemen dengan cara ini membutuhkan waktu yang lama dalam proses industri di jaman sekarang,maka sistem ini dinilai kurang efektif dan efesien. Jika hanya mengandalkan sistem manajemen dengan cara tersebut maka akan memakan banyak waktu, tenaga ,dan pikiran.dan akan berakibat industi ini tidak mengalami peningkatan yang signifikan. Selain itu perkembangan UKM ini terasa dinilai agak lambat. Oleh karena itu dirancang suatu sistem manajmen secara online dengan menggunakan media web atau internet dengan tujuan untuk meminimalkan waktu proses manajemen dan pengolahan data. tujuannya dapat meningkatkan efektifitas kerja.

Rumusan Masalah Dalam hal ini penulis akan merumuskan permasalahan yaitu : "Bagaimana membangun sebuah Sistem Informasi manajemen pada UKM bubur bayi organik Bebicare Berbasis Web"

Adapun tujuan dari penelitian ini adalah sebagai berikut :

a. Mempermudah pencatatan keuangan yang selama ini masih manual menggunakan buku besar yang kurang efisien.

b. Mempermudah dokumentasi yang harus disimpan dari manual ke digital 
Pengembangan Rekayasa dan Teknologi, Vol 16, No. 1, Juni 2020, pp 45-51

p-ISSN: 1410-9840 \& e-ISSN: 2580-8850

http://journals.usm.ac.id/index.php/jprt/index

c. Membantu effisiensi kerja dalam pencatatan data barang dan data produksi ke web dengan basis data

\section{METODE PENELITIAN}

a. Pengumpulan Data Penelitian

Dalam penelitian ini, data yang dibutuhkan adalah sebagai berikut :

i. Wawancara dengan pimpinan UKM.

ii. Requirements Definition (Analisa Kebutuhan Sistem)

iii. Perencanaan digunakan sebagai tahap awal dalam menentukan rancangan website.

iv. perancangan sistem yang baru agar masalah yang ada pada sistem lama dapat diatasi.

b. Lokasi Penelitian

Lokasi dalam penelitian ini berada di rumah produksi UKM bubur bayi organik Bebicare Sandingrowo,Soko, Tuban

c. Rancangan Penelitian

i. Analisa sistem lama

Melakukan observasi terkait tentang pencatatan data keuangan,data barang dan data karyawan yang ada.

ii. Perencaan Usulan Menganalisis kebutuhan sistem digital terkait operasional kerja dan pengolahan data.

iii. Implementasi

Penerapan sistem website pada UKM bubur bayi organik Bebicare

\section{HASIL DAN PEMBAHASAN}

a. Desain Global

Dalam pembuatan sistem informasi manajemen berbasis web ini diawali dengan proses penelusuran untuk mengidentifikasi dan menganalisis semua kebutuhan data-data yang berhubungan dengan konten dan dan fitur-fitur yang dibutuhkan. Kegiatan ini untuk memperoleh semua kebutuhan mengenai informasi setiap proses bisnis, agar model web dan prosedur manajemen memiliki kesesuaian dengan proses bisnis konvensional.Semakin banyak data yang terkumpul, berarti semakin efektif terhadap biaya dan waktu, sehingga kegiatan analisa dapat berjalan lebih cepat. Selain itu akan didapatkan hasil perhitungan yang lebih akurat. i. Dasar Perancangan sistem

Dalam implementasi Sistem Informasi Manajemen bubur bayi organik Bebicare, terdapat beberapa perangkat lunak dan perangakat keras yang digunakan penulis untuk mendukung proses perancangan web yaitu

1. PerangkatLunak (Software)

Perangkat lunak yang digunakan penulis dalam pembuatan web ini adalah:
a. Sistem Operasi : Microsoft Windows 10
b. Web Server : Apache
c. Database Server : MySQL 5.5.62
d. Database Manager : PhpMyAdmin - 4.9.0.1
e. Web Editor : Sublime Text 3

\section{Perangkat Keras (Hardware)}

Perangkat keras yang digunakan penulis dalam pembuatan sistem adalah sebagai berikut:
a. Processor: AMD A10
b. Memory : 4GB RAM

Kegiatan yang dilakukan pada tahap ini yaitu merancang atau mendesain sistem yang baik, mendesain pemodelan sistem yang baik, mengenali dan mendefinisikan masalah pembuatan sistem ini sehingga jika ada kesalahan ada alternatif pemecahannya.Selanjutnya merancang arsitektur websitenya. Model arsitektur ini sangat penting mengingat pengguna aplikasi ini adalah pemimpin UKM, admin, dan manager UKM yang membutuhkan sebuah kemudahan dalam melakukan pengumpulan data keungan,data barang dan data tansaksi pelanggan secara digital. Model arsitektur ini mendeskripsikan rancangan dari perangkat lunak di sisi webserver dan komputer client. Webserver menggunakan apache, script PHP dan database MySQL.

\section{ii. Perancangan Database}

Langkah awal dalam membangun
suatu sistem adalah melakukan
perancangan suatu sistem dengan
melakukan perancangan database yang
akan digunakan. Database ini membentuk
tabel yang akan selalu digunakan untuk
menyimpan berbagai informasi yang
digunakan dan juga digunakan dalam
pengolahan data.
Dalam Sistem ini memerlukan tabel:


Pengembangan Rekayasa dan Teknologi, Vol 16, No. 1, Juni 2020, pp 45-51

p-ISSN: 1410-9840 \& e-ISSN: 2580-8850

http://journals.usm.ac.id/index.php/jprt/index

1) Tabel User

Nama Tabel : user

Fungsi: penyimpanan data user

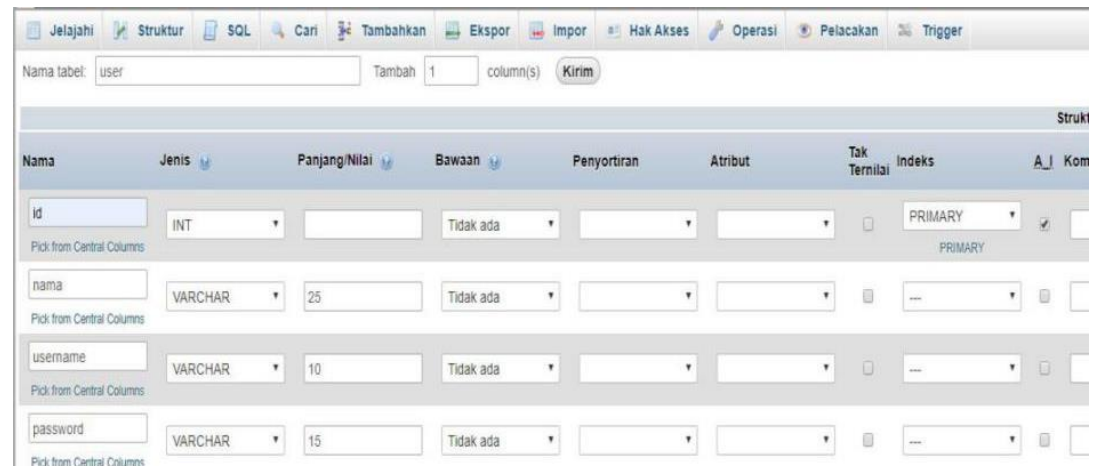

Gambar 1. Tabel user

2) Tabel Keuangan

Nama Tabel : keuangan

Fungsi: penyimpanan data keuangan,pengeluaran,saldo

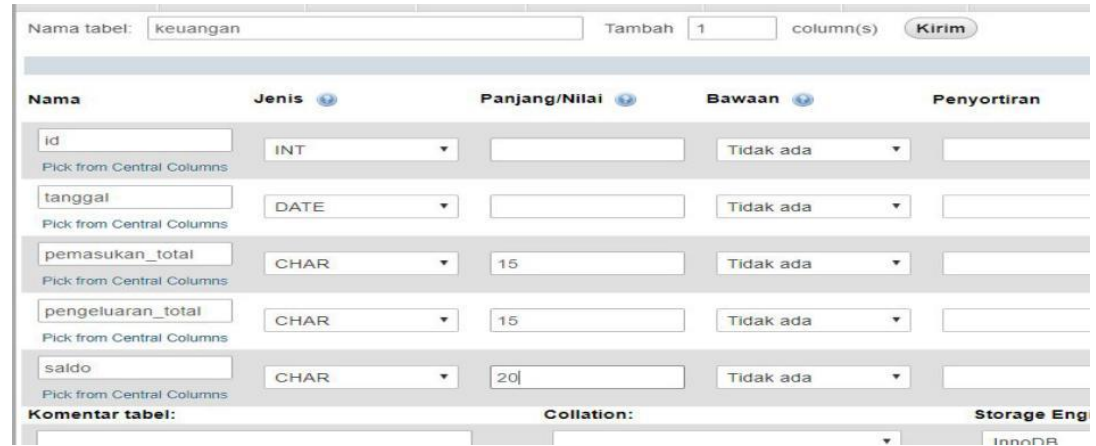

Gambar 2. Tabel Keuangan

3) Tabel Data Karyawan

Nama Tabel : karyawan

Fungsi: penyimpanan data karyawan,jumlah hari kerja

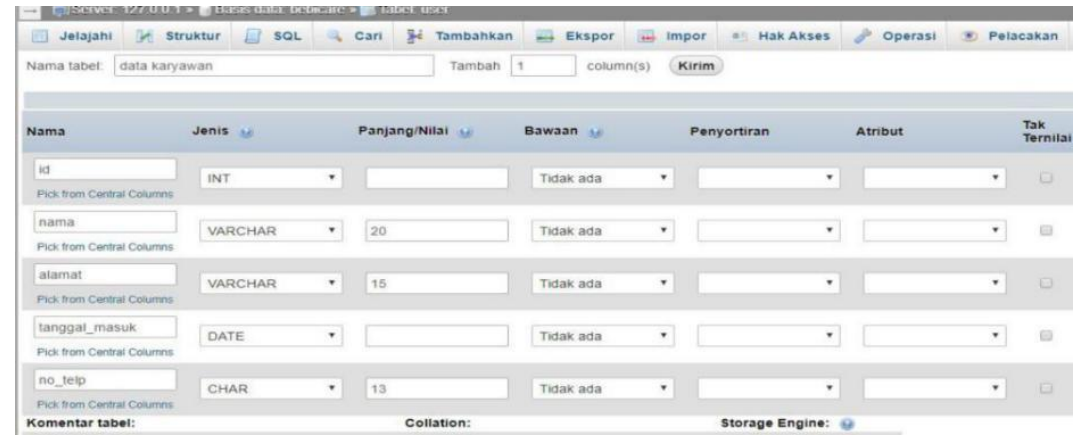

Gambar 3. Tabel data karyawan

4) Tabel Data Produksi

Nama Tabel : produski

Fungsi : penyimpanan data produksi 
Pengembangan Rekayasa dan Teknologi, Vol 16, No. 1, Juni 2020, pp 45-51

p-ISSN: 1410-9840 \& e-ISSN: 2580-8850

http://journals.usm.ac.id/index.php/jprt/index

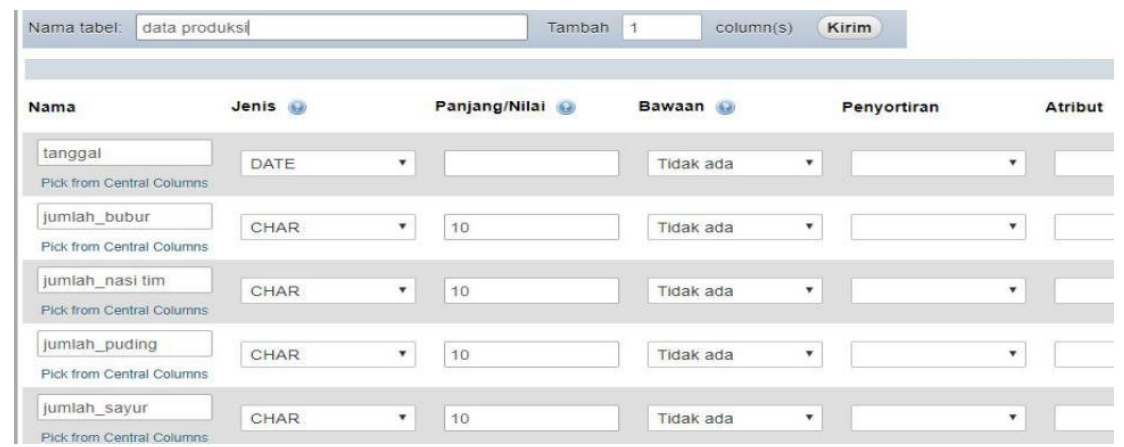

Gambar 4 Tabel Data Produksi

5) Tabel data omset outlet

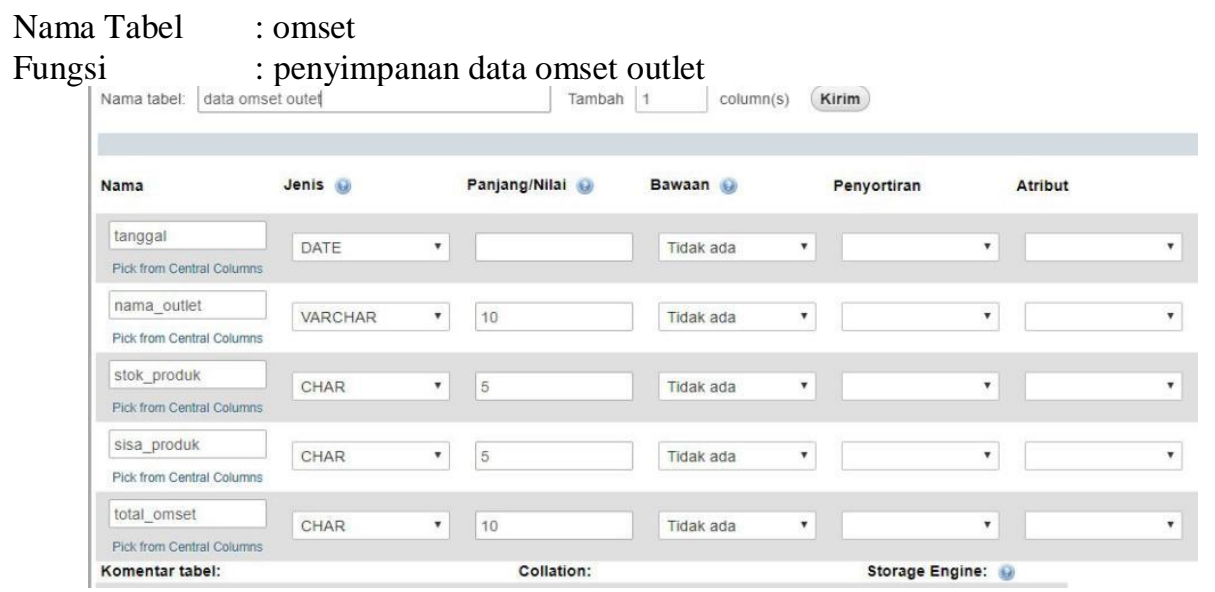

Gambar 5. Tabel Data Omset Outlet

\section{iii. Hasil Implementasi}

untuk menghasilkan suatu tampilan yang baik, mudah dipakai, dan lain-lain. Untuk lebih jelasnya tentang gambaran rancangan tampilan websitei ini,Hasil implementasi pada Sistem Informasi Manajemen Griya Arinda terdiri dari form-form sebagai berikut :

1) Form login

Form Login, biasanya digunakan untuk membatasi hak akses bagi user untuk melihat dan berinteraksi dengan data. Hanya user yang sudah terdaftar yang bisa mengakses data-data ini.Form Login ini memiliki tiga tipe user yaitu sebagai author yaitu manager dan pemimpin UKM yang bisa mengakses semua data yang ada di website ini dan tipe kedua yaitu admin, hanya bisa mengakses beberapa menu saja yang dijinkan pemimpin UKM. Dan yang terakhir adalah tipe karyawan yang hanya bisa mngakses menu data omset outlet untuk mengisi laporan hasil penjualan outletnya.

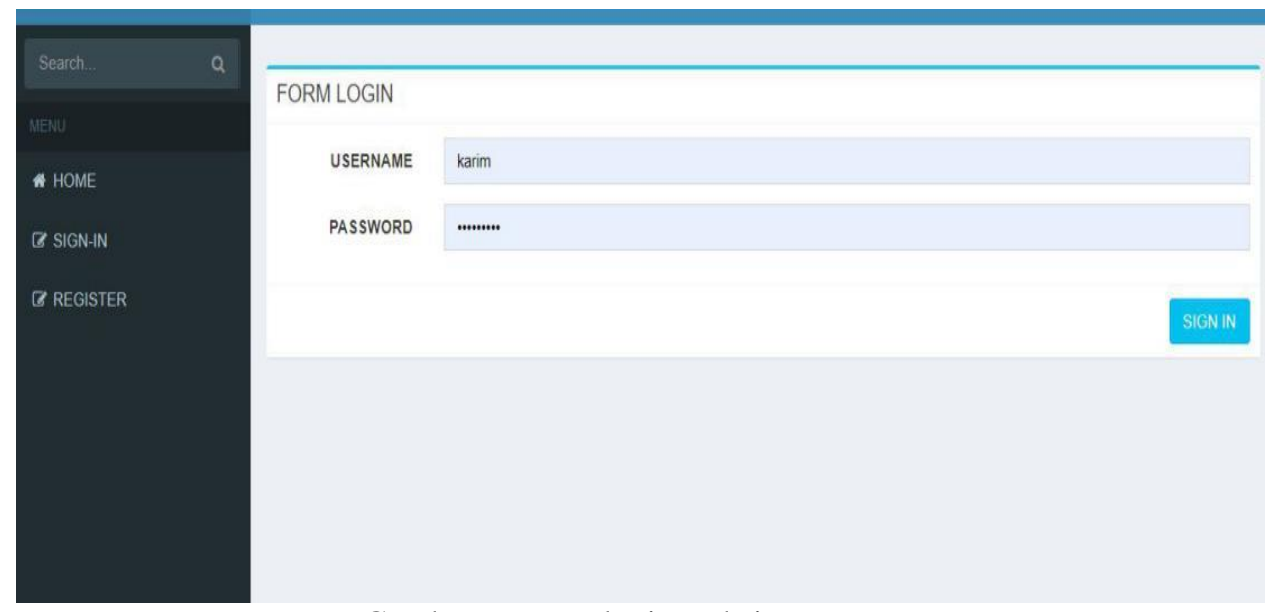

Gambar 6. Form login website 
Pengembangan Rekayasa dan Teknologi, Vol 16, No. 1, Juni 2020, pp 45-51

p-ISSN: 1410-9840 \& e-ISSN: 2580-8850

http://journals.usm.ac.id/index.php/jprt/index

2) Form Menu Utama

Menu utama adalah tampilan awal yang terlihat setelah user melakukan login,yang berisi sambutan dan beberapa menu utama

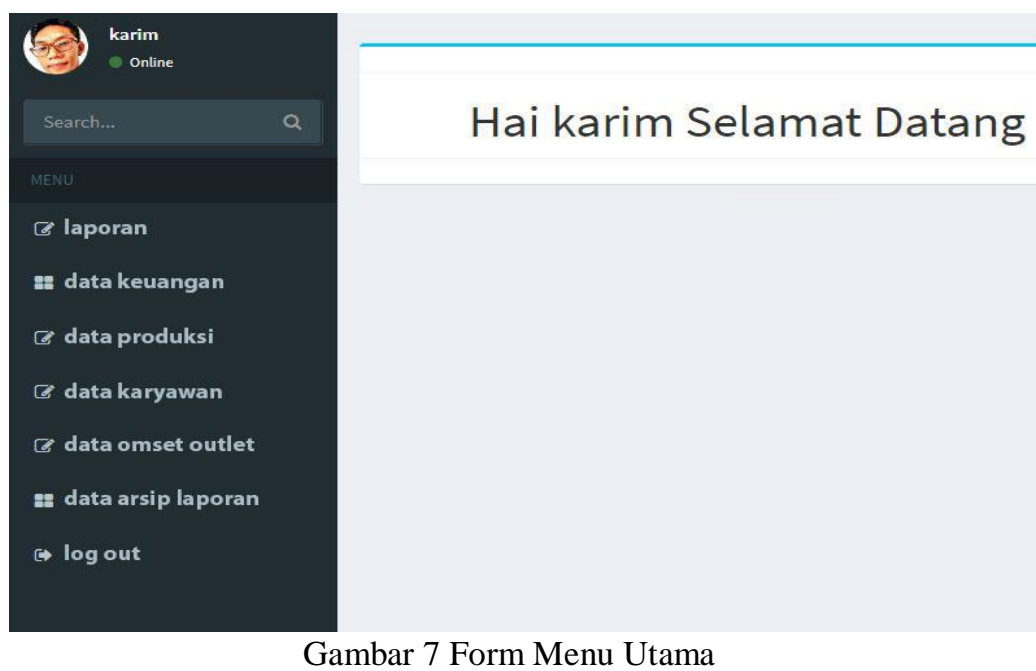

3) Form data produksi

Form data produksi ini muncul setelah user mengeklik menu data produksi yang berisi data produksi UKM untuk hari esok yang bisa diubah dan ditambah oleh admin

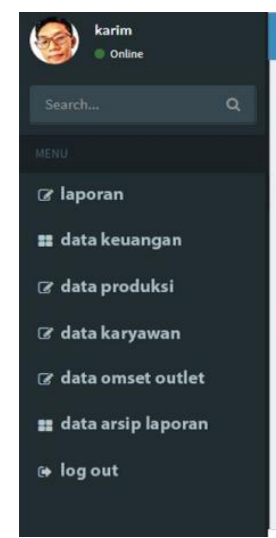

4)

\section{Form data keuangan}

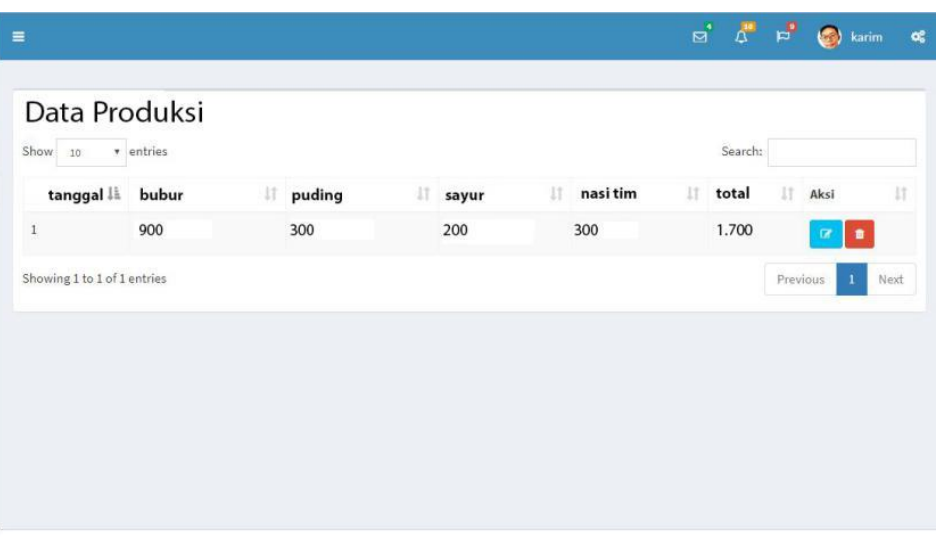

Gambar 8. Form Data Produksi

Form data produksi ini muncul setelah user mengeklik menu data keuangan yang berisi data pemasukan,pengeluaran,dan saldo keuangan

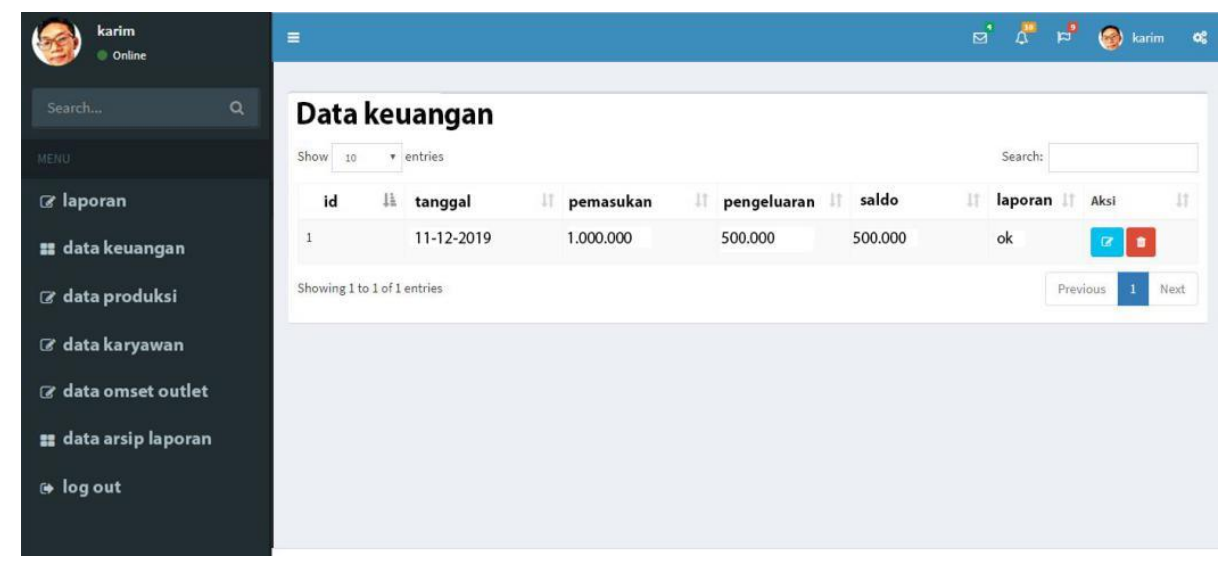

Gambar 9. Form Data Keuangan 
Pengembangan Rekayasa dan Teknologi, Vol 16, No. 1, Juni 2020, pp 45-51

p-ISSN: 1410-9840 \& e-ISSN: 2580-8850

http://journals.usm.ac.id/index.php/jprt/index

\section{5) Form data karyawan}

Form data karyawam ini muncul setelah user mengeklik menu data karyawan yang berisi data identitas karyawan dan jumlah hari kerja untuk menentukan gaji, jika karyawan yang dimaksud hari itu masuk maka jumlah hari kerjanya akan bertambah 1 yang akan diisi oleh admin UKM.

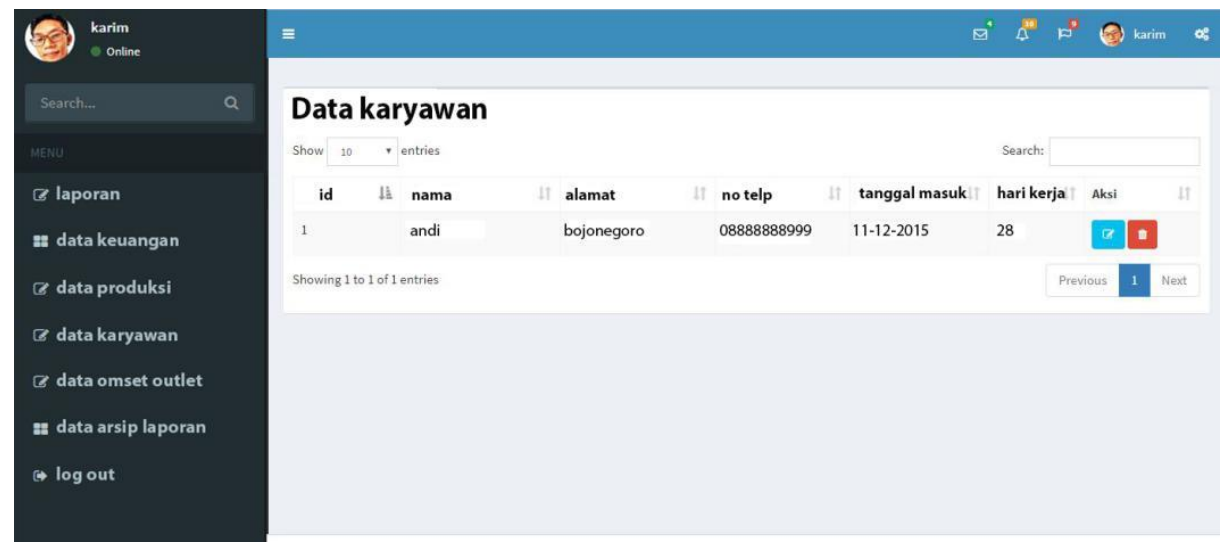

Gambar 9. Form Data Karyawan

\section{6) Form data omset outlet}

Form data omset ini muncul setelah user mengeklik menu data omset outlet yang berisi form untuk penjaga outlet mengisi hasil penjualan produk pada hari itu dan juga melaporkan stok awal dan produk yang tersisa

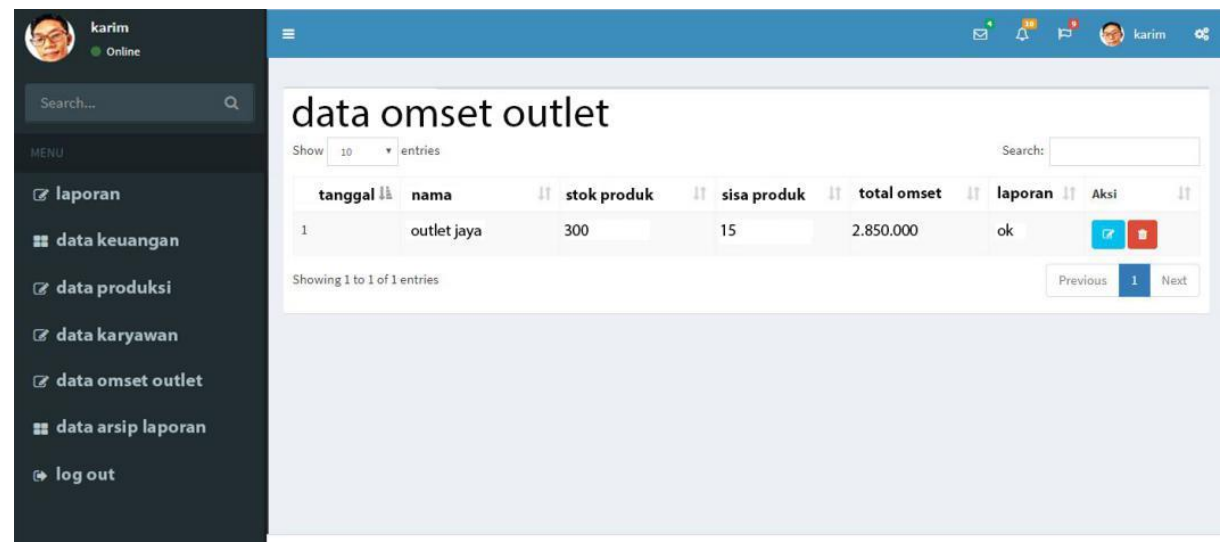

\section{7) Form laporan}

Form laporan muncul setelah user mengeklik menu laporan, menu ini hanya bisa diakses oleh manajer dan pemimpin UKM untuk mengecek dan memanajemen hasil laporan dari karyawan dan admin yang berisi total keuangan jumlah karyawan dan perhitungan gajinya serta manajer dan pimipinan bisa mencetak/print laporan di menu ini, isi dari menu ini akan direset ulang setelah 1 bulan dan data -data dibulan sebelumnya akan otomatis tersimpan di menu data arsip laporan. 
Pengembangan Rekayasa dan Teknologi, Vol 16, No. 1, Juni 2020, pp 45-51

p-ISSN: 1410-9840 \& e-ISSN: 2580-8850

http://journals.usm.ac.id/index.php/jprt/index

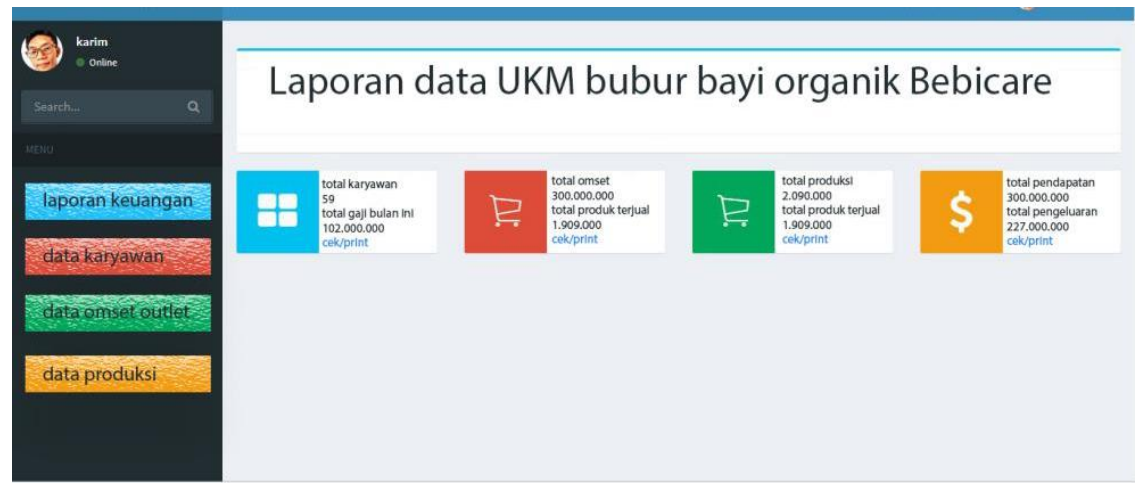

\section{KESIMPULAN}

Gambar 11. Form laporan

Berdasarkan hasil pembahasan yang telah penulis diuraikan, maka dapat diambil kesimpulan bahwa, implementasi Sistem Informasi Manajemen Pada UKM bubur bayi organik Bebicare dengan kegunaan untuk pencatatan penjualan bubur,pencatatan keuangan, pencatatan karyawan, perhitungan gaji karyawan, data produksi dan laporan keuangan.dan secara rincinya:

a. Dengan adanya sistem yang telah dibuat untuk UKM bubur bayi organik Bebicare dapat mempermudah dan mempercepat dalam proses pencarian data keuangan, karyawan,data produksi dan mempermudah dalam pembuatan laporan.

b. Dengan adanya sistem website, admin lebih mudah dalam mengsis dan mengedit laporan keuangan.

c. Dengan adanya sistem website, Manajer lebih mudah dalam mengkontrol dan mengawasi laporan penjualan.

d. Dengan adanya sistem website, pemimpin UKM lebih mudah dalam mengkontrol dan mengawasi laporan keuangan.

e. Sistem yang dibuat dapat mempermudah dalam pencarian informasi sesuai dengan kebutuhan.

\section{DAFTAR PUSTAKA}

[1] Kadir,A.,2003,PemrogramanWEB Mencakup : HTML,CSS, JavaScript \& PHP, edisi 1, Andi.

[2] Kusyawatno, L., 2006. Mahir dan Terampil Berkomputer.Grafindo

[3] Napompech, K., 2014, Attributes Influencing Wedding Studia Choice, Journal of Applied Sciences, tersedia pada: http://docsdrive.com/pdfs/ansinet/jas/201 4/2685-2694.pdf, tanggal akses: 15 februari 2016.

[4] Power, M., 2011, Mobile Web Apps, tersedia pada: http://publications.cetis.org.uk /wpcontent/uploads/2011/10/Mobile_Web_ Apps.pdf, tanggal akses: 15 Februari 2016.
[5] Ramadhan, Arief, 2006. "Pemograman Web Database dengan PHP dan MySQL., Jakarta : PT. Elex Media Komputindo.

[6] Abryandoko,EW.2019. "Studi Penerepan Value Stream Mapping Untuk Mengurangi Pemborosan Pada Proses Suplay Chain". Solo : Seminar Nasional IENACO 